\title{
Nutrition Intake, Health Status, Education and Economic Growth: A Causality Investigation
}

\author{
Rahman Olanrewaju Raji* \\ *Canterbury International High School, Lekki, Nigeria
}

Submitted: January 14, $2020 \bullet$ Accepted: May 15, 2020

\begin{abstract}
This paper examines the causal relationship between nutrition intake, health status, education and economic growth within a six-variate VEC framework, forecast error variance decomposition and impulse response function techniques, covering the period from 1990 to 2013, using quarterly data in Nigeria. This paper includes control variables in order to eliminate variable omission bias, unlike most existing studies. The results suggest the presence of long-run, bicausal relationships between the candidate variables of the study. In addition, the short-run unidirectional causal relationships are found between main variables, including a causal relationship running from nutrition and fiscal policy to education, as well as a causal link running from education and economic growth to health status. These findings support the existing theories. The results based on the model and empirical data suggest that the government should allocate more resources to human development in order to enhance productivity and boost economic growth. Similarly, there is a need to design adequate mechanisms to ensure proper allocation of the limited resources and avoid their embezzlement by corrupt government officials.
\end{abstract}

JEL classification: C22, H52, I19, I39

Keywords: nutrition intake, health status, education, economic growth

*Corresponding Author. Email: rahmandole@gmail.com, rahman.raji@rocketmail.com 


\section{Introduction}

An economy with lack of progress in economic development could be associated with continuous productivity loss in economic growth due to the absence of investment or insufficient investments in human welfare in terms of adequate and good nutritional intake as well as human capital (health and education) which form a basis for development. The nutritional improvements are prerequisite for good health, high labour productivity and increased life expectancy. A healthy population tends to be less susceptible to disease, more alert and more energetic. These conditions, in turn, might contribute to an increase in economic earning and growth. In addition, the fact that investing in nutrition is a necessity, not a luxury proves its significance with respect to both intellectual and educational powers. An economy's population with a high rate of growth retardation tends to be associated with substantial reduction in mental capacity or cognitive abilities, and adverse school or academic performance, which ultimately leads to reduced work productivity. The failure of policy planners, policy makers and authorities without political will to invest adequately in health and education of the citizens as well as their nutritional intake, eventually devastates health status of the citizens. Unhealthy situations or environments might potentially have an adverse impact on education in the long run and, ultimately, exert a negative effect on labour force productivity and efficiency. This, in turn, generates more loss of output growth and development.

The majority of literature captures the relationship between either health or education, and economic growth, while few studies focus on the role of nutrition in economic growth. This study explores six-way causality between these variables including control variables (fiscal policy and inflation rate), where this causality direction between candidate variables can implant the strategies of human capital development for the economy due to the fact that the strategic direction is very important for the improvement of citizens' health status. In addition, none of the existing studies has investigated the dynamic interactions between education, health status, nutrition intake and macroeconomic variables (economic growth, fiscal policy and inflation) adopting the VEC model in a small-open economy like Nigeria by assessing six-way causality nexus.

\section{Literature Review}

Based on the argument that causality exists either between health and education, or between health and economic growth, or between health, education and economic growth, very few studies disclose causality between nutrition and economic growth. Studies by Hassan and Kalim (2012); Afzal et al. (2013); Ayuba (2014); Yun and Yusoff (2015); Ämiri and Linden (2016); Ogundari and Aromolaran (2017); Şen et al. (2018); Ubi-Abai and George-Anokwuru (2018) are among empirical studies that tested causal linkages between health, education, nutrition and economic growth. Those studies could either 
involve bivariate or trivariate causal relationships. Some of them are time-series based, while others are both time series and cross-section based (i.e. panel data analysis).

Regarding the causality test either bivariate or trivariate relationships between health, education and economic growth, the country-specific studies, based on time-series, are as follows. Afzal et al. (2013) conducted an empirical study examining the cointegration and the causality between education, health, food inflation, and economic growth in Pakistan. The study revealed that education had a direct impact on economic growth both in the short- and in the long run, including two-way causality between economic growth and education, and excluding causality between health and economic growth. Afzal et al. (2013) deviated from Hassan and Kalim (2012), who investigated long-run relationship and causality between real GDP per capita, per capita education expenditures, and per capita health expenditures in Pakistan from 1972 to 2009. Their findings showed the existence of bidirectional relationship between per capita real GDP and per capita education expenditures in the short run, whereas per capita health expenditures and real GDP per capita did not Granger-cause each other. In the long run, there existed bidirectional granger causality between real GDP per capita, per capita education expenditures and per capita health expenditures. In the same vein, Yun and Yusoff (2015) analyzed the impact of education expenditure and health care expenditure on economic growth in Malaysia by employing Pair Wise Granger Causality test to explore time series data over the period from 1980 to 2012. Findings suggested the presence of unidirectional causality that ran from GDP to the public education expenditure. One-way causality was also found running from GDP to the public health care spending.

Adeyemi and Ogunsola (2016) investigated the impact of human capital development (education and health) on economic growth in Nigeria using time series data spanning from 1980 to 2013 with ARDL cointegration analysis. The findings showed that there was a negative long run relationship between primary, tertiary school enrolment, public expenditure on health and economic growth. Ayuba (2014) pinpointed the causal relationship between public social expenditure (education and health) and economic growth in Nigeria for the period from 1990 to 2009 by applying the Vector Error Correction (VEC) Model Based Causality. His study revealed unidirectional causality running from both economic growth to health expenditure and from economic growth to education and aggregate social expenditure. Aka and Dumont (2008) tested the causal relationships between human capital (health and education) and economic growth (GDP per capita) for the USA using time series approach. The EC-VAR investigations reported bidirectional causality between human capital variables and growth. The estimates of variance decomposition and impulse response functions suggested that the long run dynamics of economic growth could be explained by the past education level, while a lesser part of these variations were related to health level. Rahman (2011) agreed with Aka and Dumont (2008) who investigated the causal relationship between health expenditure, education expenditure and GDP for Bangladesh using time series data for the period from 1990 to 2009. The study 
discovered bidirectional causality between education expenditure and GDP and also between education expenditure and health expenditure. Unidirectional causality was found running from health expenditure to GDP.

Tang (2011) investigated the relationship between health care spending, income and relative price in Malaysia with annual samples from 1970 to 2009 by employing Granger causality test. The results demonstrated that, in the long run, health care spending and income had bidirectional Granger causality. Ubi-Abai and George-Anokwuru (2018) found the determinants of human capital formation based on evidence from Nigeria. He discovered significant and positive bidirectional relationships between health expenditures and economic growth. Ubi-Abai and George-Anokwuru (2018) drew similar conclusions to Ogungbenle et al. (2014), who tested the nexus between life expectancy, public health spending and economic growth in Nigeria. The data obtained from a vector autoregressive (VAR) model, confirmed that there was bidirectional causality between public health spending and economic growth in Nigeria.

Dawson (2002) analyzed data from Pakistan, covering the period from 1961 to 1998, to examine long-run relationships between daily per capita calorie intake and per capita income, using cointegration method. It was found that there existed unidirectional causality between income and calorie intake. These findings were consistent with Ogundari]s data (2011) for Nigeria, which was obtained by employing the Johansen method of cointegration. On the other hand, Tiffin and Dawson (2002) found a long-run income elasticity of calorie demand at 0.31 for Zimbabwe and concluded that there existed bidirectional causality between calorie intake and income.

Due to the fact that the panel data provides a time series on each cross-section unit in a group, this paper further reviews studies on panel data. SSen et al. (2018) conducted a study on the causality between education expenditure, health expenditure, and economic growth for developing countries such as Argentina, Brazil, Chile, India, Indonesia, Mexico, South Africa and Turkey over the period from 1995 to 2012 by employing the bootstrap panel Granger causality test. Findings indicated that only Brazil and Mexico displayed a significant and positive causality, running from education and health expenditure to economic growth. Indonesia had negative causality between education expenditure, health expenditure, and economic growth. No causality between these variables was found for the remaining countries.

Wang (2011) explored the causality between health care expenditure and economic growth in 31 countries from 1986 to 2007. The overall panel regression results showed that health care expenditure growth would stimulate economic growth. Wang s findings (2011) were consistent with Cooray's data (2013), which analyzed the effects of health on economic growth for a sample of 210 countries using panel data over the period from 1990 to 2008, and both the OLS and GMM approaches. The results for the full sample showed that health capital had neither robust nor significant influence on economic growth, except through their interactions with health expenditure and education in low- 
and low-middle income economies (excluding high- and upper-middle income economies). Amiri and Ventelou (2012) and Ämiri and Linden (2016) proved that, in OECD countries, the bidirectional causal relationship between GDP and health care expenditure existed in most economies. Using time series, Aslan et al. (2015) concluded that, from 1980 to 1999, seven industrialised countries had bidirectional causality, especially France, Germany and the UK, running from health care expenditure to economic growth and a unidirectional linear causality - Italy and Japan. Surprisingly, no causal relationship was found for Canada and the US.

Wang et al. (2003) discovered that there were significant short-term and long-term correlations between nutrition intake and economic growth in sub-Saharan African countries and vice versa. These conclusions supported Arcand et al.'s findings (2001). He adopted time series methods and data from sub-Saharan Africa, and concluded that inadequate nutrition results in a loss of 0.16-4.0 percentage point of GDP. In a similar study, Abdulai and Aubert (2004) investigated the effects of nutrition on the growth rate of country for four decades between 1960s and 1990s, for 43 low- and middle-income countries, utilizing ordinary least squares, instrumental variables, and random effects regressions. The results revealed that nutrition proxy by dietary supply had an effect on the economies, but the effect was not very significant for GDP growth rate per worker and labor productivity. On the contrary, capital per worker and literacy rate exerted stronger impacts on growth than DES variable. Moreover, Karlsen and Rikardson (2007) analyzed the relationship between nutrition intake (average daily calorie intake per capita and average daily protein intake per capita) and economic growth to test the direction of the growth-nutrition causality in five countries in Southern Africa. The results revealed that nutrition Granger-caused economic growth while growth Granger-causing nutrition received very little support. This did not support Ogundari and Aromolaran's results (2017) which, by using a dynamic panel causality test, revealed long- and short-run bidirectional causality between nutrition and economic growth in sub-Saharan Africa, and therefore implied that nutritional improvement was a cause and a consequence of economic growth and vice versa.

Albert and Davia (2010) discovered the link between education and health in developed countries (a sample of 11 European Union countries). The results of their study suggested a positive influence of secondary education and tertiary education on health in those European Union countries. These findings were consistent with data obtained by Fonseca and Zheng (2011) in a similar study on the causal relationship between education and health outcomes from thirteen OECD countries using IV-Probit models. The findings showed causal evidence that with numbers of years of education, the probability of reporting poor health, lower prevalence for diabetes and hypertension decreased. Similarly to Albert and Davia (2010) and Fonseca and Zheng (2011), Al-shihri (2014) results, obtained by using multivariate Granger causality approaches, suggested a unidirectional causality where education Granger-caused health expenditure both in the short- and in the long run, indicating that expenditure on education should enhance health status in 
Saudi Arabia.

In conclusion, the outcomes of most studies, associated with causality test either between health and economic growth nexus, education and economic growth relationship or health-education and economic growth relationship, are mixed. Most studies are characterized by the omission of the variable bias on the course of causality testing, while many studies adopted ARDL model. This study includes relevant variables as intervening variables (fiscal policy and inflation rate), which can influence nutrition intake, health status, education and economic growth. Unlike others, this study rejects the ARDL approach and employs multivariate VEC causality model and dynamic interactions between the candidate variables in order to determine the causal direction between those variables of interest and political decisions.

\section{Model Estimation}

This study attempts to explore the empirical relationship between the nutrition intake, health status, education and economic growth by applying the multivariate JohansenJuselius cointegration approach (see Johansen (1988); Johansen and Juselius (1990)) to determine long-run relationships and short-run dynamics between nutrition status, health status, education and economic growth, including control variables (inflation and real exchange rate) developed by Johansen (1988) and Johansen and Juselius (1990). This estimation technique has several advantages in comparison to previous, traditional cointegration methods. Firstly, it has superior properties for two- and more variable system. Secondly, the multivariate Johansen-Juselius cointegration approach assumes that all variables in the system are endogenous. Multivariate cointegration approach of Johansen (1988) and Johansen and Juselius (1990) is based on vector error correction model (VECM) which can be applied in the following way.

$$
\Delta X_{t}=\beta_{0}+\sum_{i=1}^{n-1} \Pi \Delta X_{t-1}+\beta_{1} X_{t-1}+\varepsilon_{t}
$$

where $\Delta$ denotes the first difference operator, $\Pi$ is a $(n \times n)$ coefficient matrix, whose rank determines the number of cointegrating vectors, if $\Pi$ is of either full rank or zero rank $\Pi=0$, there will be no cointegration between the elements in the long-run relationship, it indicates that it will be appropriate to estimate the model in level or first difference respectively. If $\Pi$ is of reduced form, $r$ (where $r$ is less than $n)$ then there will exit $(n \times r)$ matrices, $\alpha$ and $\beta$ such that $\Pi=\alpha \beta$ where $\beta$ is the matrices, whose column are the linearly independent cointegrating vector and $\alpha$ matrix is interpreted as the adjustment matrix indicating the speed with the system responds to last period deviation each endogenous variable. Cointegration techniques of Johansen and Juselius (1990) offer two test statistics to verify the number of cointegrated vectors or ranks of the matrix which 
are trace statistics, $\operatorname{LR}(\lambda$ trace) and the maximum eigen value, $\operatorname{LR}(\lambda \max )$.

\subsection{The Granger Causality Test Specification}

In order to test the short- and the long-run causal linkages between nutrition status, health status, education and growth rate, this study specifies approaches which involve a system of six sets of equations. In addition, we agree with Akinlo and Egbetunde (2010) that some macro variables tend to have a great impact on one another, i.e., that nutrition intake, heath status, education and growth rate can influence each other, and that their omission could bias the direction of causality between them. In view of this, our study includes the following control variables: fiscal policy and inflation rate. Fiscal policy is related to government policy actions due to different responses to any cyclical movement in an economy. Inflation rate is a monetary variable which has direct or indirect impact on most macroeconomic parameters.

In order to examine the short- and the long-run causal linkages between nutrition status, health status, education and growth rate, the Vector Error correction models are to be employed to test the Granger-causality. It has been decided because the Vector Error Correction models suggests that change in the dependent variables in response to changes in the explanatory variables intend to establish the long-run relation between the variables. The models are presented below.

$$
\begin{aligned}
\Delta \mathrm{NU}_{t}= & \gamma_{1}+\sum_{i=1}^{n} \alpha_{10, i} \Delta \mathrm{NU}_{t-i}+\sum_{i=0}^{n} \alpha_{11, i} \Delta \mathrm{HE}_{t-i}+\sum_{i=0}^{n} \alpha_{12, i} \Delta \mathrm{ED}_{t-i}+\sum_{i=0}^{n} \alpha_{13, i} \Delta \mathrm{GR}_{t-i} \\
& +\sum_{i=0}^{n} \alpha_{14, i} \Delta \mathrm{IF}_{t-i}+\sum_{i=0}^{n} \alpha_{15, i} \Delta \mathrm{FP}_{t-i}+\beta_{16} \mathrm{ECM}_{t-1}+\mu_{1, t} \\
\Delta \mathrm{HE}_{t}= & \gamma_{2}+\sum_{i=1}^{n} \alpha_{20, i} \Delta \mathrm{HE}_{t-i}+\sum_{i=0}^{n} \alpha_{21, i} \Delta \mathrm{NU}_{t-i}+\sum_{i=0}^{n} \alpha_{22, i} \Delta \mathrm{ED}_{t-i}+\sum_{i=0}^{n} \alpha_{23, i} \Delta \mathrm{GR}_{t-i} \\
& +\sum_{i=0}^{n} \alpha_{24, i} \Delta \mathrm{IF}_{t-i}+\sum_{i=0}^{n} \alpha_{25, i} \Delta \mathrm{FP}_{t-i}+\beta_{26} \mathrm{ECM}_{t-1}+\mu_{2, t} \\
\Delta \mathrm{ED}_{t}= & \gamma_{3}+\sum_{i=1}^{n} \alpha_{30, i} \Delta \mathrm{ED}_{t-i}+\sum_{i=0}^{n} \alpha_{31, i} \Delta \mathrm{HE}_{t-i}+\sum_{i=0}^{n} \alpha_{32, i} \Delta \mathrm{NU}_{t-i}+\sum_{i=0}^{n} \alpha_{33, i} \Delta \mathrm{GR}_{t-i} \\
& +\sum_{i=0}^{n} \alpha_{34, i} \Delta \mathrm{IF}_{t-i}+\sum_{i=0}^{n} \alpha_{35, i} \Delta \mathrm{FP}_{t-i}+\beta_{36} \mathrm{ECM}_{t-1}+\mu_{3, t} \\
\Delta \mathrm{GR}_{t}= & \gamma_{4}+\sum_{i=1}^{n} \alpha_{40} \Delta \mathrm{GR}_{t-i}+\sum_{i=0}^{n} \alpha_{41} \Delta \mathrm{HE}_{t-i}+\sum_{i=0}^{n} \alpha_{42} \Delta \mathrm{ED}_{t-i}+\sum_{i=0}^{n} \alpha_{43} \Delta \mathrm{NU}_{t-i} \\
& +\sum_{i=0}^{n} \alpha_{44} \Delta \mathrm{IF}_{t-i}+\sum_{i=0}^{n} \alpha_{45} \Delta \mathrm{FP}_{t-i}+\beta_{46} \mathrm{ECM}_{t-1}+\mu_{4, t}
\end{aligned}
$$




$$
\begin{aligned}
\Delta \mathrm{IF}_{t}= & \gamma_{5}+\sum_{i=1}^{n} \alpha_{50} \Delta \mathrm{IF}_{t-i}+\sum_{i=0}^{n} \alpha_{51} \Delta \mathrm{HE}_{t-i}+\sum_{i=0}^{n} \alpha_{52} \Delta \mathrm{ED}_{t-i}+\sum_{i=0}^{n} \alpha_{53} \Delta \mathrm{NU}_{t-i} \\
& +\sum_{i=0}^{n} \alpha_{54} \Delta \mathrm{IF}_{t-i}+\sum_{i=0}^{n} \alpha_{55} \Delta \mathrm{FP}_{t-i}+\beta_{56} \mathrm{ECM}_{t-1}+\mu_{5, t} \\
\Delta \mathrm{FP}_{t}= & \gamma_{6}+\sum_{i=1}^{n} \alpha_{60, i} \Delta \mathrm{IF}_{t-i}+\sum_{i=0}^{n} \alpha_{61, i} \Delta \mathrm{HE}_{t-i}+\sum_{i=0}^{n} \alpha_{62, i} \Delta \mathrm{ED}_{t-i}+\sum_{i=0}^{n} \alpha_{63, i} \Delta \mathrm{NU}_{t-i} \\
& +\sum_{i=0}^{n} \alpha_{64, i} \Delta \mathrm{GR}_{t-i}+\sum_{i=0}^{n} \alpha_{65, i} \Delta \mathrm{IR}_{t-i}+\beta_{66} \mathrm{ECM}_{t-1}+\mu_{6, t}
\end{aligned}
$$

where NU, HE, ED, GR, IF and FP are nutrition intake, health status, education, growth rate, inflation rate and real exchange rate respectively; $\alpha$ and $\gamma$ are the parameters of the models, $\Delta$ is the first difference operator; $\mathrm{t}$ is the time period, $\mathrm{ECM}_{t-1}$ is the error correction term and $\mu_{t}$ is the mutually uncorrelated white noise residual. The coefficients of the ECM variables contain information about whether the past values of variables affect the current values of the variables under study. The size and statistical significance of the coefficient of the error correction term in each ECM model measure the tendencies of each variable to return to the equilibrium.

In order to examine the short- and the long-run causal linkages between nutrition status, health status, education and growth rate following the previous works, evidence suggests that once there are long-run relations between variables (in this case nutrition status, health status, education, growth rate and control variables), then there are cases for causality in one or more directions (Narayan and Smyth, 2005). Nevertheless, we could only establish the direction of the long-run causality between the variables by conducting a test of statistical significance (a $t$-test) on the lagged error-correction term in each equation. The direction of the short-run causal relationships between the variables could also have been established by conducting a joint test of statistical significance, (i.e. an $F$-test), of the explanatory variables in each of the equations (see Oh and Lee, 2004, Narayan and Smyth, 2005). However, the non-significance of both the t-test(s) as well as the $F$-tests in the VECM would indicate econometric exogeneity of the dependent variables. With VEC approach, the Granger exogeneity or endogeneity of the dependent variable as well as understanding of the Granger causality would be indicated by VEC approach within the sample period (M. Masih et al, 1996).

In order to analyze the dynamic properties of the system or relative strength of the candidate variables of interest (nutrition status, health status, education and growth rate) beyond the sample period and the dynamic interaction of the various shocks in the post sample period, Variance decompositions test (VDCs) and the Impulse response functions (IRFs) were computed. Thus, model variables are converted to first difference prior to estimation of the model. All the variables are at the levels except economic growth and fiscal policy which were in their logarithm form to avoid measurement error and to provide reliable estimates. 


\subsection{Data Definition and Sources}

The study has been carried out using quarterly data over the period from 1990Q1 to 2013Q4. These periods are set due to the fact that some of the data got reported in 1990 and they are annual data which were converted into quarterly data using an EViews package for analysis. The data related to economic growth, education (secondary school enrollment) and health (life expectancy at birth) were sourced from World Development Indicator. Fiscal policy and inflation rate were obtained from Central Bank of Nigeria database, whereas nutrition evidence (dietary energy supply) was sourced from Our World in Data.

\section{Empirical Results and Discussion of Results}

\subsection{Descriptive Statistics of Data Series}

Table 1: Descriptive Statistics of Data Series.

\begin{tabular}{lcccccc}
\hline & LOG(ED) & FP & GR & LOG(IF) & LOG(HE) & LOG(NU) \\
\hline Mean & 3.417508 & 0.075833 & 5.725000 & 2.671138 & 3.824940 & 7.861870 \\
Median & 3.342249 & -0.326407 & 5.237500 & 2.519970 & 3.802207 & 7.871394 \\
Maximum & 4.113820 & 9.497500 & 21.36875 & 4.336383 & 4.029473 & 7.911965 \\
Minimum & 3.152721 & -9.350000 & -2.081250 & 1.586809 & 3.671559 & 7.661762 \\
Std. Dev. & 0.261566 & 4.254695 & 4.211669 & 0.737806 & 0.104083 & 0.051756 \\
Skewness & 0.752077 & 0.056784 & 0.799664 & 0.808540 & 0.551553 & -1.842210 \\
Kurtosis & 2.439618 & 2.444690 & 4.023252 & 2.793177 & 2.078368 & 6.506394 \\
Jarque-Bera & 10.30603 & 1.285066 & 14.41957 & 10.63089 & 8.265001 & 103.4790 \\
Probability & 0.005782 & 0.525959 & 0.000739 & 0.004915 & 0.016043 & 0.000000 \\
Observations & 96 & 96 & 96 & 96 & 96 & 96 \\
\hline
\end{tabular}

Table 1 presents the summary statistics of the sample data and the variables used for the analysis. The descriptive statistics show that the mean values of school enrollment and inflation rate over the given period are 3.418 and 2.671 respectively, with their median values at 3.342 and 2.519 respectively. The maximum and minimum values for school enrollment are 4.114 and 3.153 respectively, while maximum and minimum values for inflation rate are 4.336 and 1.586 respectively. The mean values of the health status and nutrition over the given period are 3.825 and 7.862 respectively, with median values of 3.802 and 7.871 respectively. The maximum and minimum values for the health status are 4.029 and 3.672 respectively, whereas the maximum and minimum values for nutrition are 7.912 and 7.662 respectively. As regards dispersion, the four variables recorded low values of standard deviation. The means that the medians of all of the variables (school enrollment, health status, nutrition status and inflation rate) lie between the maximum and minimum values, which implies that the variables have a high tendency to be normally distributed. The mean values of the fiscal policy and economic growth over the 
given period are 0.076 and 5.725 respectively, with median values at -0.325 and 5.238 respectively. The maximum and minimum values for the fiscal policy are 9.498 and -9.350 respectively, whereas the maximum and minimum values for economic growth are 21.369 and -2.081 respectively. The values indicate that fiscal policy and economic growth over the given period have witnessed disparity, which implies that they were high in some years and abysmally lower than the observed average in other. The dispersion is confirmed by the relatively high standard deviation values for fiscal policy and economic growth at 4.255 and 4.212 respectively.

With respect to skewness of the variable, since all of the variables lie within 1.0 and -1.0 , all the distributions of the variables are symmetrical because the skewness is not substantial. As regards the Kurtosis statistic, which measures the peakedness or flatness of the distribution of the series, a Gaussian distribution is expected to have kurtosis of 3.0. Since all of the variables lie within the range of 3, except for nutrition status, the implication is that most variables have a high tendency to be normally distributed. Finally, the Jarque-Bera test revealed that the variables are not normally distributed (except for the fiscal policy with $p$-value at 0.526 ), which means that we reject $H_{0}$, indicating that the hypothesis of normality in the distribution cannot be accepted. The outcomes suggest that some of the data were unreliable. Hence, it is necessary to incorporate econometric tests to validate the data reliability for a valid inference from our study.

\subsection{Stationarity Test}

Due to unreliability of some variables in the descriptive statistics, the unit root test in time series econometric became necessary to confirm the state of stationarity of each variable in the study. The author of this study decided to determine the order of integration of all of the data before estimation of the data using VEC. Table 2 below shows the results of the Augmented Dickey-Fuller (ADF) unit root tests for the order of integration of the variables under investigation.

Table 2: Unit Root Test Results (ADF Test)

\begin{tabular}{lcccccc}
\hline Variables & FP & GR & $\log (\mathbf{E D})$ & $\log (\mathbf{I F})$ & $\log (\mathbf{H E})$ & $\log (\mathbf{N U})$ \\
\hline Level & $-3.235^{* *}$ & -0.665 & 1.818 & -0.699 & 0.306 & 1.088 \\
First Difference & $-4.232^{*}$ & $-5.802^{*}$ & $-5.820^{*}$ & $-2.488^{* * *}$ & $-3.75^{*}$ & $-3.175^{* *}$ \\
\hline \multicolumn{2}{c}{ Note: Significance level: } & $1 \%(-3.62)(*), 5 \%(-2.94)\left({ }^{* *}\right)$ and & $10 \%(-2.61)\left({ }^{* * *}\right)$
\end{tabular}

The results of the Augmented Dickey-Fuller (ADF) unit root test indicate the stationarity properties of selected variables without taking into account the intercept and the trend properties. The results showed that, with the exception of fiscal policy, all other variables were not characterized by the unit root at level, and all of the variables revealed evidence of stationarity at first difference, mostly at a 5 percent significance level. What follows is that the ADF test validated the descriptive statistics of our study; therefore, all 
of the variables are integrated of order 1, which lends support to the use of VEC.

\subsection{The Results of Multivariate Johansen Cointegration Test}

Table 3 presents the cointegration relationship between selected variables under the multivariate Johansen Maximum Likelihood approach. This approach has two statistics, trace ( $\lambda$ trace) and maximal eigen value $(\lambda \max )$ They suggested that there were four cointegrating vectors in each statistic in this study. Therefore, the results rejected the null hypothesis of no cointegrating vectors in favour of the superior four cointegrating vectors at five percent significance level mostly. This implies that a long-run relationship exists among the selected variables, i.e. economic growth, education, health status, nutrition status, inflation and fiscal policy in Nigeria.

Table 3: The Results of Multivariate Johansen Cointegration Test

\begin{tabular}{|c|c|c|c|c|c|c|c|c|c|}
\hline \multicolumn{5}{|c|}{$\mathbf{L R}(\lambda \max )$} & \multicolumn{5}{|c|}{$\mathbf{L R}(\lambda$ trace $)$} \\
\hline Null & Alternative & statistic & $\begin{array}{c}\text { Critical } \\
\text { value } \\
95 \%\end{array}$ & $\begin{array}{c}\text { Critical } \\
\text { value } \\
\mathbf{9 0 \%}\end{array}$ & Null & Alternative & statistic & $\begin{array}{c}\text { Critical } \\
\text { value } \\
95 \%\end{array}$ & $\begin{array}{c}\text { Critical } \\
\text { value } \\
90 \%\end{array}$ \\
\hline$r=0$ & $r=1$ & $108.34^{*}$ & 36.27 & 33.48 & $r=0$ & $R>1$ & $226.52^{*}$ & 83.18 & 78.47 \\
\hline$R \leq 1$ & $R=2$ & $53.92^{*}$ & 29.95 & 27.57 & $R \leq 1$ & $R \geq 2$ & $117.97^{*}$ & 59,33 & 55.42 \\
\hline$R \overline{\leq} 2$ & $R=3$ & $40.42^{*}$ & 23.92 & 21.58 & $R \leq \bar{x} 2$ & $R \geq 3$ & $64.06^{*}$ & 39.81 & 36.69 \\
\hline$R \leq 3$ & $R=4$ & $15.72^{* *}$ & 17.68 & 15.57 & $R \leq 3$ & $R \geq 4$ & $23.64^{* *}$ & 24.05 & 21.46 \\
\hline$R \leq \overline{\leq} 4$ & $R=5$ & 5.84 & 11.03 & 928 & $R \overline{\leq} 4$ & $R \geq 5$ & 7.92 & 12.36 & 10.25 \\
\hline$R \leq 5$ & $R=6$ & 2.08 & 4.16 & 3.04 & $R \leq 5$ & $R \geq 6$ & 2.08 & 4.16 & 3.04 \\
\hline
\end{tabular}

\subsection{Granger Causality Results based on Vector Error Correction Model}

As regards the evidence of cointegration relationship between the analyzed variables, it is of our interest to conduct the Granger causality test in order toto suggest appropriate economic policies and human development policies by understanding the directions of causality between economic growth, inflation rate, fiscal policy, education, and nutrition intake and health status. Therefore, the Granger causality in the vector error correction mechanism is used to verify the directions of causality between the aforementioned variables as well as to decompose the directions of causality into the short- and the long-run effects. The study conducted short-run causality tests using $p$-values and test for the significance of the lagged error-correction terms, $\mathrm{ECM}_{t-1}$, in order to establish the long-run causality between the explanatory variables and the dependent variable, using the $t$-test error correction model stipulated above.

As one can see in Table 4, the long-run relationship, verified by the significance of the ECM term, implies that there is an evidence of four causal relationships, namely (1) from fiscal policy, education, inflation, health status, nutrition intake to economic growth; (2) from fiscal policy, economic growth, education, inflation, health status to and nutrition intake, and (3) from fiscal policy, economic growth, education, inflation rate, 
nutrition intake to health status. There are bidirectional causal relationships among the variables which are supported by the negativity and significance of the error correction term of equations: economic growth, health status and nutrition intake with least a 5 percent significance level of the $t$-test.

Table 4: Granger Causality Analysis

\begin{tabular}{|c|c|c|c|c|c|c|c|}
\hline \multicolumn{7}{|c|}{$F$-statistic } & \multirow{2}{*}{$\begin{array}{c}\mathbf{E C M}_{(t-1)} \\
\text { coefficient } \\
(t \text {-statistic) }\end{array}$} \\
\hline Variables & $\Delta \mathrm{FP}$ & $\Delta \mathrm{GR}$ & $\Delta(\log E D)$ & $\Delta(\log I F)$ & $\Delta(\operatorname{LogHE})$ & $\Delta(\log N \mathrm{U})$ & \\
\hline \multirow{2}{*}{$\Delta \mathrm{FP}$} & - & 0.63 & 0.38 & 0.66 & 0.13 & 0.01 & 0.08 \\
\hline & - & $(0.428)$ & $(0.534)$ & $(0.418)$ & $(0.715)$ & $(0.895)$ & $(0.324)$ \\
\hline \multirow[t]{2}{*}{$\Delta \mathrm{GR}$} & 1.02 & - & 0.10 & 1.39 & 0.02 & 1.27 & -0.56 \\
\hline & $(0.316)$ & - & $(0.749)$ & $(0.241)$ & $(0.876)$ & $(0.262)$ & $(-4.59)^{*}$ \\
\hline \multirow[t]{2}{*}{$\Delta(\log E D)$} & 6.04 & 0.15 & - & 0.00 & 1.56 & 3.74 & 0.00 \\
\hline & $(0.016)^{* * *}$ & $(0.695)$ & - & (0.958) & $(0.215)$ & $(0.056)^{* * *}$ & $(0.262)$ \\
\hline \multirow{2}{*}{$\Delta(\log I F)$} & 0.05 & 0.89 & 0.77 & - & 0.21 & 0.37 & 0.01 \\
\hline & $(0.827)$ & $(0.347)$ & $(0.382)$ & - & $(0.644)$ & $(0.546)$ & $(0.43)$ \\
\hline \multirow[t]{2}{*}{$\Delta(\operatorname{LogHE})$} & 0.01 & 3.24 & 2.78 & 0.00 & - & 2.97 & -0.01 \\
\hline & $(0.917)$ & $(0.075)$ & $(0.099) * * *$ & $(0.912)$ & - & $(0.088) * * *$ & $(-2.49) * *$ \\
\hline \multirow[t]{2}{*}{$\Delta(\log N U)$} & 0.04 & 0.61 & 0.04 & 0.65 & 0.08 & - & 0.00 \\
\hline & $(0.833)$ & $(0.437)$ & $(0.841)$ & $(0.420)$ & $(0.779)$ & - & $(1.55)^{* *}$ \\
\hline
\end{tabular}

In the short run, the evidence of a unidirectional causality relationship exists between fiscal policy and education. The education equation reveals a short-run causal flow from fiscal policy to education with a $p$-value at 0.016 associated with the joint statistical test of significance of education at a 5 percent significance level. Similarly, there is an evidence for a distinct unidirectional short-run causal relationship between education and nutrition intake. From education equation, it displays a short-run causal flow from nutrition intake to education whose $p$-value indicates 0.056 associated with the joint statistical test of significance at a 5 percent significance level. Therefore, our results lend support to the fact that there is a distinct unidirectional short-run causal flow from economic growth to health intake, a one way direction running from education to health intake, an unidirectional short-run causal flow from nutrition intake to health status with $p$-values at 0.075 , 0.098 and 0.088 , associated with the joint statistical test of significance at a 10 percent significance level of explanatory variables respectively.

Therefore, the significance of the error correction term cannot be ruled out. It indicates that the burden of the short-run endogenous adjustment (to the long-term trend) to bring the system back to its long-run equilibrium has to be taken by economic growth, health status and nutrient intake. The VECM results indicate that, in the short run, education stands out econometrically exogenous as evidence in the statistical significance of the $t$-test of the lagged error correction term.

To this end, the Granger causality analysis has been constrained to in-sample test and 
Figure 1: Impulse Response Functions (IRF) results - 20 quarters

Response of LOG(ED) to Cholesky One S.D. Innovations

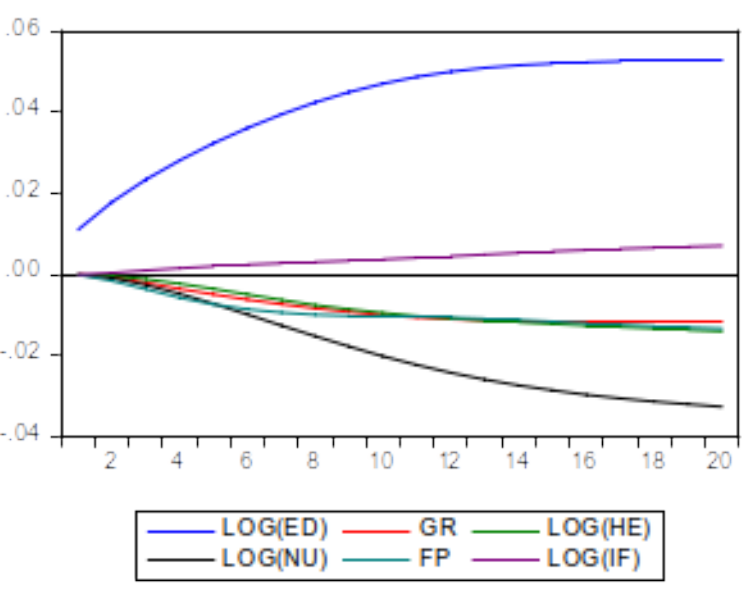

Response of LOG(HE) to Cholesky One S.D. Innovations

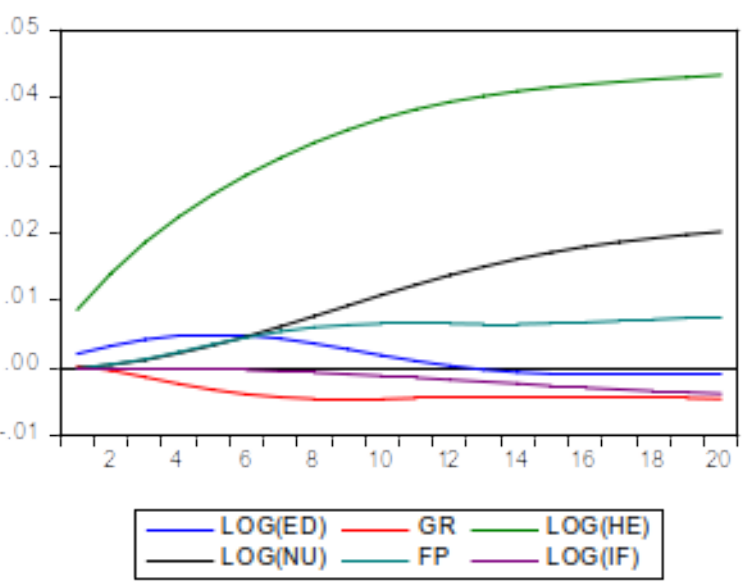

Response of FP to Cholesky One S.D. Innovations

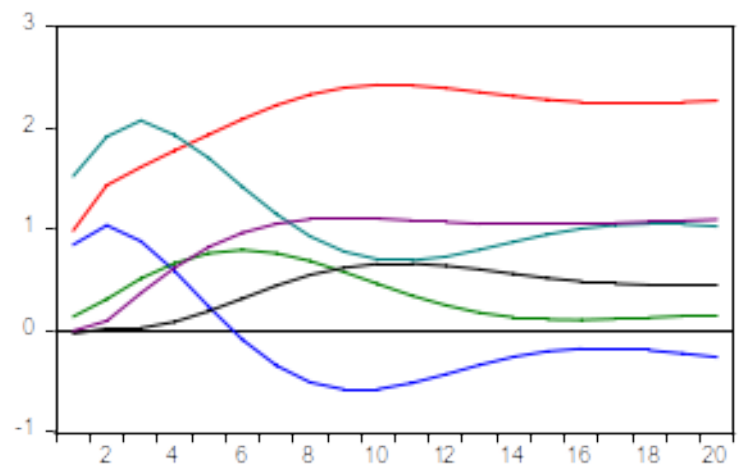

Response of GR to Cholesky One S.D. Innovations

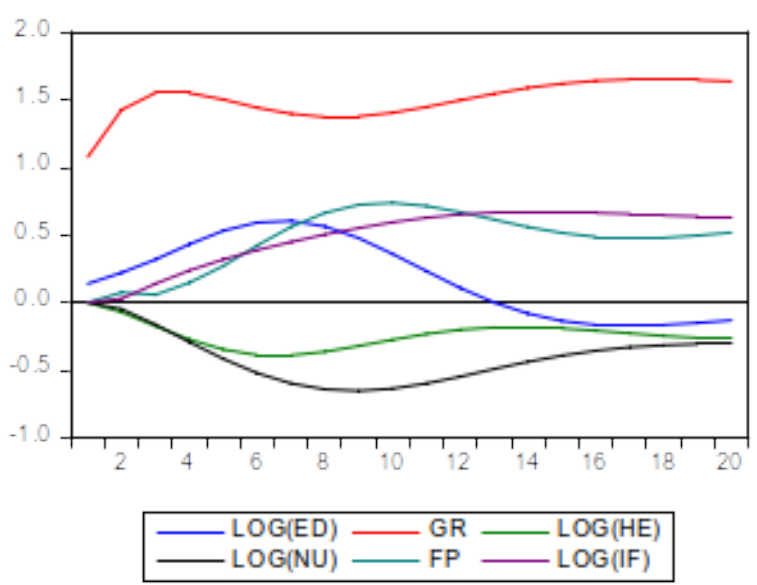

Response of LOG(NU) to Cholesky One S.D. Innovations

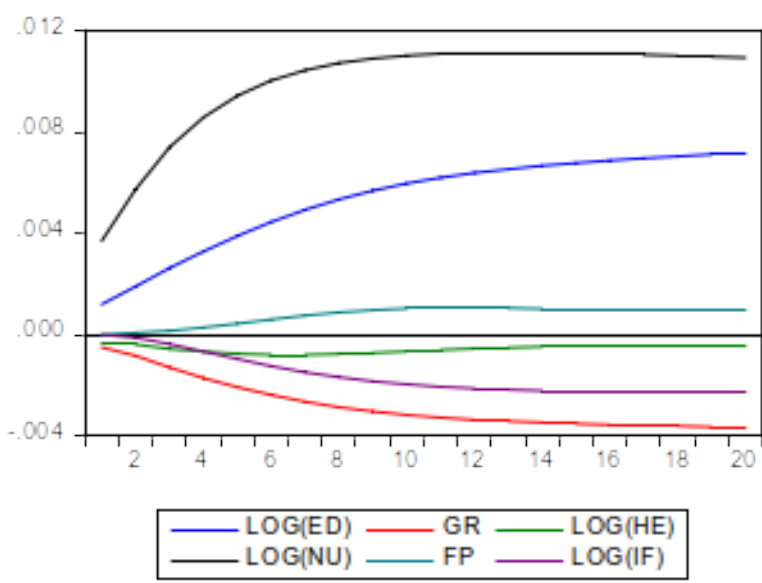

Response of LOG(IF) to Cholesky One S.D. Innovations

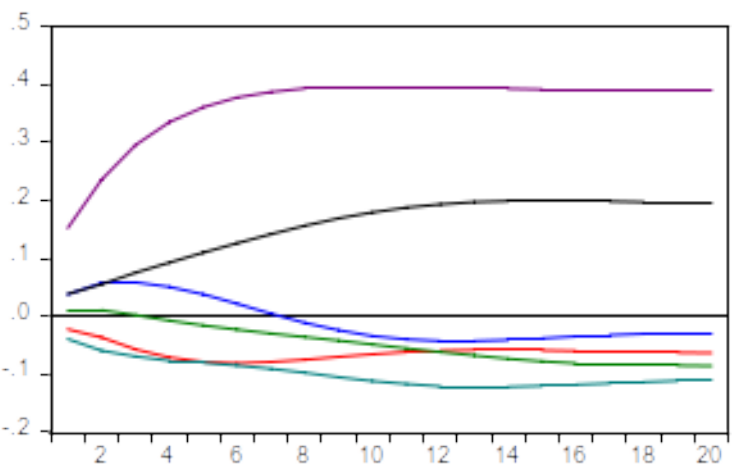

$-\mathrm{LOG}(\mathrm{ED})-\mathrm{GR}-\mathrm{LOG}(\mathrm{HE})$
$\mathrm{LOG}(\mathrm{NU})-\mathrm{FP}-\mathrm{LOG}(\mathrm{IF})$


has not considered the dynamic interaction of the variables beyond the sample period. The forecast error variance decomposition analysis has been included in order to provide information about the relative strength of random shock in the system. Table 5 (af) summarizes the results of the variance decomposition up to 20 years horizons. To explain the shock to economic growth from candidate variables of interest, health is more important than nutrition and education both in the short- and in the long run. At $20^{\text {th }}$ period, 10.5 percent, 3.7 percent, 1.2 percent, 10.3 percent and 5.6 percent of the variation in forecast error variance for economic growth are explained by health, education, nutrition, fiscal policy and inflation respectively. To explain the shock to education based on candidate variables of interest, fiscal policy is more important both in the short- and in the long run than the candidate variables of interest. At $20^{\text {th }}$ period, 11.8 percent, 1 percent, 0.4 percent and 0.3 percent of the variation in forecast error variance for education are explained by fiscal policy, health, education and nutrition respectively. To explain the shock to health with candidate variables of interest, in the short run, education is more important than economic growth and nutrition, including fiscal policy, , and, in the long run economic growth and nutrition are more significant than education. At $20^{\text {th }}$ period, 13.6 percent, 0.9 percent, 0.5 percent, 1.6 percent and 1.2 percent of the variation in forecast error variance for health are explained by economic growth, nutrition, education, fiscal policy and inflation respectively. To explain the shock to nutrition, education is more important than economic growth and health both in the short and in the long run. At $20^{\text {th }}$ period, 16.2 percent, 1.4 percent, 0.3 percent, 1.4 percent and 0.3 percent of the variation in forecast error variance for nutrition are explained by education, economic growth, health, fiscal policy and inflation respectively.

Table 5: Variance Decomposition Test

(a) Variance Decomposition Test of Fiscal Policy

\begin{tabular}{ccccccc}
\hline Periods & $\Delta \mathrm{FP}$ & $\Delta \mathrm{GR}$ & $\Delta(\log \mathrm{ED})$ & $\Delta(\log \mathrm{IF})$ & $\Delta(\log \mathrm{HE})$ & $\Delta(\operatorname{logNU})$ \\
\hline 1 & 100.0000 & 0.000000 & 0.000000 & 0.000000 & 0.000000 & 0.000000 \\
3 & 96.80634 & 2.671156 & 0.028804 & 0.016891 & 0.407628 & 0.069184 \\
5 & 91.91441 & 7.059052 & 0.282985 & 0.012610 & 0.645392 & 0.085548 \\
7 & 88.78903 & 9.822339 & 0.523740 & 0.011944 & 0.753983 & 0.098963 \\
9 & 86.89159 & 11.49503 & 0.679732 & 0.011774 & 0.813687 & 0.108186 \\
12 & 85.12926 & 13.04893 & 0.824177 & 0.011526 & 0.869148 & 0.116959 \\
14 & 84.33686 & 13.74771 & 0.888932 & 0.011406 & 0.894194 & 0.120897 \\
16 & 83.72660 & 14.28587 & 0.938802 & 0.011314 & 0.913484 & 0.123929 \\
18 & 83.24220 & 14.71304 & 0.978388 & 0.011241 & 0.928795 & 0.126336 \\
20 & 82.84838 & 15.06033 & 1.010572 & 0.011182 & 0.941243 & 0.128293 \\
\hline
\end{tabular}


(b) Variance Decomposition Test of Economic Growth

\begin{tabular}{ccccccc}
\hline Periods & $\Delta \mathrm{FP}$ & $\Delta \mathrm{GR}$ & $\Delta(\log \mathrm{ED})$ & $\Delta(\log \mathrm{IF})$ & $\Delta(\log \mathrm{HE})$ & $\Delta(\operatorname{logNU})$ \\
\hline 1 & 12.41427 & 87.58573 & 0.000000 & 0.000000 & 0.000000 & 0.000000 \\
3 & 9.363129 & 86.80892 & 0.299356 & 2.108117 & 1.214428 & 0.206052 \\
5 & 9.231776 & 83.78392 & 0.475536 & 2.979441 & 3.172961 & 0.356363 \\
7 & 9.489743 & 80.74602 & 1.069802 & 3.501171 & 4.689967 & 0.503295 \\
9 & 9.662064 & 78.19422 & 1.635004 & 3.931726 & 5.936284 & 0.640706 \\
12 & 9.855889 & 74.99459 & 2.339068 & 4.483146 & 7.510537 & 0.816774 \\
14 & 9.965871 & 73.16993 & 2.738752 & 4.798576 & 8.409770 & 0.917101 \\
16 & 10.06404 & 71.54359 & 3.094988 & 5.079665 & 9.211215 & 1.006500 \\
18 & 10.15210 & 70.08509 & 3.414480 & 5.331730 & 9.929928 & 1.086671 \\
20 & 10.23151 & 68.76976 & 3.702614 & 5.559051 & 10.57809 & 1.158974 \\
\hline
\end{tabular}

(c) Variance Decomposition Test of Education

\begin{tabular}{ccccccc}
\hline Periods & $\Delta \mathrm{FP}$ & $\Delta \mathrm{GR}$ & $\Delta(\log \mathrm{ED})$ & $\Delta(\log \mathrm{IF})$ & $\Delta(\log \mathrm{HE})$ & $\Delta(\log \mathrm{NU})$ \\
\hline 1 & 20.79260 & 0.184722 & 79.02268 & 0.000000 & 0.000000 & 0.000000 \\
3 & 15.77597 & 0.168558 & 83.38550 & 0.001340 & 0.521091 & 0.147539 \\
5 & 14.10123 & 0.248289 & 84.73014 & 0.000973 & 0.703416 & 0.215950 \\
7 & 13.26871 & 0.298946 & 85.38350 & 0.001026 & 0.798546 & 0.249273 \\
9 & 12.78958 & 0.327732 & 85.75951 & 0.001067 & 0.853235 & 0.268884 \\
12 & 12.35901 & 0.353078 & 86.09786 & 0.001096 & 0.902375 & 0.286584 \\
14 & 12.17080 & 0.364116 & 86.24579 & 0.001108 & 0.923865 & 0.294324 \\
16 & 12.02817 & 0.372483 & 86.35789 & 0.001117 & 0.940150 & 0.300189 \\
18 & 11.91635 & 0.379044 & 86.44577 & 0.001125 & 0.952918 & 0.304787 \\
20 & 11.82634 & 0.384325 & 86.51652 & 0.001130 & 0.963196 & 0.308488 \\
\hline
\end{tabular}

(d) Variance Decomposition Test of Inflation

\begin{tabular}{ccccccc}
\hline Periods & $\Delta \mathrm{FP}$ & $\Delta \mathrm{GR}$ & $\Delta(\log \mathrm{ED})$ & $\Delta(\log \mathrm{IF})$ & $\Delta(\log \mathrm{HE})$ & $\Delta(\operatorname{logN\mathrm {U}})$ \\
\hline 1 & 2.872254 & 1.692458 & 9.375289 & 86.06000 & 0.000000 & 0.000000 \\
3 & 4.268161 & 3.770983 & 8.130636 & 83.66341 & 0.076136 & 0.090678 \\
5 & 6.274341 & 7.547628 & 6.593760 & 79.33236 & 0.169738 & 0.082170 \\
7 & 7.330185 & 9.816256 & 5.576861 & 76.99499 & 0.202337 & 0.079370 \\
9 & 7.901022 & 11.09047 & 4.984205 & 75.73107 & 0.216368 & 0.076871 \\
12 & 8.394522 & 12.19373 & 4.467583 & 74.64154 & 0.228113 & 0.074513 \\
14 & 8.606320 & 12.66655 & 4.246289 & 74.17415 & 0.233187 & 0.073506 \\
16 & 8.765388 & 13.02164 & 4.080121 & 73.82310 & 0.237000 & 0.072751 \\
18 & 8.889220 & 13.29808 & 3.950759 & 73.54981 & 0.239968 & 0.072163 \\
20 & 8.988354 & 13.51938 & 3.847197 & 73.33103 & 0.242344 & 0.071692 \\
\hline
\end{tabular}


(e) Variance Decomposition Test of Health Status

\begin{tabular}{ccccccc}
\hline Periods & $\Delta \mathrm{FP}$ & $\Delta \mathrm{GR}$ & $\Delta(\log \mathrm{ED})$ & $\Delta(\log \mathrm{IF})$ & $\Delta(\log \mathrm{HE})$ & $\Delta(\operatorname{logNU})$ \\
\hline 1 & 0.717148 & 0.000279 & 3.268477 & 0.621183 & 95.39291 & 0.000000 \\
3 & 0.400387 & 2.205721 & 2.402560 & 0.787816 & 93.64939 & 0.554125 \\
5 & 0.844895 & 6.545048 & 1.627710 & 0.867315 & 89.41589 & 0.699139 \\
7 & 1.137181 & 9.206943 & 1.193408 & 0.972454 & 86.71260 & 0.777413 \\
9 & 1.290956 & 10.70110 & 0.943872 & 1.037402 & 85.20165 & 0.825018 \\
12 & 1.422002 & 11.99927 & 0.724179 & 1.094052 & 83.89269 & 0.867801 \\
14 & 1.478375 & 12.55770 & 0.629582 & 1.118353 & 83.32975 & 0.886242 \\
16 & 1.520806 & 12.97787 & 0.558421 & 1.136633 & 82.90616 & 0.900111 \\
18 & 1.553885 & 13.30543 & 0.502946 & 1.150885 & 82.57593 & 0.910923 \\
20 & 1.580396 & 13.56796 & 0.458486 & 1.162308 & 82.31127 & 0.919587 \\
\hline
\end{tabular}

(f) Variance Decomposition Test of Nutrition Intake

\begin{tabular}{ccccccc}
\hline Periods & $\Delta \mathrm{FP}$ & $\Delta \mathrm{GR}$ & $\Delta(\log \mathrm{ED})$ & $\Delta(\log \mathrm{IF})$ & $\Delta(\log \mathrm{HE})$ & $\Delta(\operatorname{logNU})$ \\
\hline 1 & 0.347217 & 0.366865 & 11.67167 & 4.494021 & 1.167913 & 81.95231 \\
3 & 0.777714 & 0.215718 & 12.97527 & 3.934270 & 0.729147 & 81.36788 \\
5 & 1.417614 & 0.571409 & 14.00981 & 3.727287 & 0.545005 & 79.72887 \\
7 & 1.784322 & 0.865330 & 14.76947 & 3.534484 & 0.457370 & 78.58902 \\
9 & 1.990279 & 1.036404 & 15.24305 & 3.417240 & 0.408945 & 77.90408 \\
12 & 2.172402 & 1.186559 & 15.66761 & 3.312953 & 0.365855 & 77.29462 \\
14 & 2.251797 & 1.251848 & 15.85228 & 3.267589 & 0.347040 & 77.02944 \\
16 & 2.311931 & 1.301303 & 15.99212 & 3.233236 & 0.332790 & 76.82862 \\
18 & 2.359049 & 1.340054 & 16.10168 & 3.206319 & 0.321625 & 76.67127 \\
20 & 2.396961 & 1.371235 & 16.18985 & 3.184659 & 0.312641 & 76.54466 \\
\hline
\end{tabular}

So far, the causal effect with the Granger causality test and the forecast error variance decomposition analysis have been examined and reported in Table 4 and 5 respectively. Previous analyses provide only the direction of causality, but they are unable to explain the sign (i.e. positive or negative) of the causal relationship. They are also unable to determine the for how long these impacts are required to take place in the system. Hence, the impulse response function (IRF) is employed in order to trace out the response to a shock to each of the variables in the system. The results of the IRF are presented in Table 6 (a-f) and Figure 1. The result of IRF demonstrates that at the 20-quarter horizon, a shock in nutrition exerts a positive impact on economic growth. A shock in nutrition leads to a rise in economic growth throughout the 20 -quarter horizon. A shock in health has a persistent negative impact on economic growth throughout the period. A shock in education leads to a decrease in economic growth around positive level till $5^{\text {th }}$ quarter period after which a decline occurs around negative level till $20^{\text {th }}$ quarter period. A shock in nutrition has a negative effect on education over the $20^{\text {th }}$ quarter period. Significantly, there is a positive and mild impact of a shock in fiscal policy on education shock. Economic growth shock and health shock in response to education shock imply that negative relationships, climaxing at 0.01 and 0.02 at twenty quarter for economic growth and health respectively, are statistically insignificant. A shock in nutrition ensures a 
positive impact at a sharp increase in the health throughout the 20-quarter horizon. A shock in education promotes health over twentieth quarter period where there is a mild increase around the positive level. Whereas the response of health shocks to economic growth shocks is asymmetrical over the 20-quarter horizons with low impact. A shock in economic growth increases nutrition intake after third quarter period which continues to rise around positive level throughout the 20-quarter horizons. A shock in education tends to have a gentle increase in nutrition intake around positive level for the whole 20-quarter periods. The response of nutrition intake shocks to health shocks is asymmetrical over the 20-quarter horizons with a sharp and mild impact.

Table 6: Impulse Response Function

(a) Impulse Response of Fiscal Policy

\begin{tabular}{ccrrrrr}
\hline Periods & $\Delta \mathrm{FP}$ & \multicolumn{1}{c}{$\Delta \mathrm{GR}$} & $\Delta(\log \mathrm{ED})$ & $\Delta(\log \mathrm{IF})$ & $\Delta(\log \mathrm{HE})$ & $\Delta(\operatorname{logNU})$ \\
\hline 1 & 2.367531 & 0.000000 & 0.000000 & 0.000000 & 0.000000 & 0.000000 \\
3 & 5.272296 & -0.719939 & -0.069359 & -0.055384 & -0.283260 & 0.118271 \\
5 & 7.988032 & -1.957837 & -0.346331 & -0.058058 & -0.610387 & 0.223591 \\
7 & 10.67591 & -3.266786 & -0.691030 & -0.028068 & -0.928311 & 0.337700 \\
9 & 13.36970 & -4.571402 & -1.041262 & 0.003820 & -1.241100 & 0.453906 \\
12 & 17.41286 & -6.524015 & -1.564700 & 0.050798 & -1.709642 & 0.628491 \\
14 & 20.10833 & -7.825559 & -1.913389 & 0.082018 & -2.022089 & 0.744848 \\
16 & 22.80377 & -9.127132 & -2.262086 & 0.113242 & -2.334542 & 0.861203 \\
18 & 25.49921 & -10.42871 & -2.610787 & 0.144468 & -2.646995 & 0.977558 \\
20 & 28.19466 & -11.73029 & -2.959489 & 0.175693 & -2.959447 & 1.093913 \\
\hline
\end{tabular}

(b) Impulse Response of Economic Growth

\begin{tabular}{cccrrrr}
\hline Periods & \multicolumn{1}{c}{$\Delta \mathrm{FP}$} & $\Delta \mathrm{GR}$ & $\Delta(\log \mathrm{ED})$ & $\Delta(\log \mathrm{IF})$ & $\Delta(\log \mathrm{HE})$ & $\Delta(\operatorname{logNU})$ \\
\hline 1 & 0.412659 & 1.096093 & 0.000000 & 0.000000 & 0.000000 & 0.000000 \\
3 & 0.574100 & 2.123066 & 0.109197 & -0.289504 & -0.217095 & 0.090671 \\
5 & 0.394710 & 2.591266 & 0.017358 & -0.506000 & -0.518958 & 0.177001 \\
7 & 0.185483 & 2.968470 & -0.155279 & -0.692875 & -0.806671 & 0.267471 \\
9 & -0.017106 & 3.349273 & -0.335180 & -0.876707 & -1.088273 & 0.360724 \\
12 & -0.317949 & 3.925732 & -0.602852 & -1.153267 & -1.509846 & 0.501076 \\
14 & -0.518458 & 4.310334 & -0.780949 & -1.337774 & -1.790993 & 0.594598 \\
16 & -0.718989 & 4.694901 & -0.959055 & -1.522278 & -2.072147 & 0.688118 \\
18 & -0.919522 & 5.079462 & -1.137167 & -1.706780 & -2.353301 & 0.781637 \\
20 & -1.120056 & 5.464022 & -1.315279 & -1.891282 & -2.634455 & 0.875157 \\
\hline
\end{tabular}


(c) Impulse Response of Education

\begin{tabular}{cccccrr}
\hline Periods & $\Delta \mathrm{FP}$ & $\Delta \mathrm{GR}$ & $\Delta(\log \mathrm{ED})$ & $\Delta(\log \mathrm{IF})$ & $\Delta(\log \mathrm{HE})$ & $\Delta(\operatorname{logNU})$ \\
\hline 1 & 0.005439 & -0.000513 & 0.010604 & 0.000000 & 0.000000 & 0.000000 \\
3 & 0.011916 & -0.001257 & 0.028184 & $7.33 \mathrm{E}-05$ & -0.001788 & -0.000932 \\
5 & 0.018327 & -0.002451 & 0.046076 & $8.52 \mathrm{E}-05$ & -0.003724 & -0.002041 \\
7 & 0.024663 & -0.003717 & 0.063936 & 0.000151 & -0.005694 & -0.003158 \\
9 & 0.031002 & -0.004980 & 0.081790 & 0.000217 & -0.007662 & -0.004277 \\
12 & 0.040514 & -0.006869 & 0.108575 & 0.000316 & -0.010613 & -0.005957 \\
14 & 0.046855 & -0.008127 & 0.126431 & 0.000382 & -0.012581 & -0.007076 \\
16 & 0.053196 & -0.009386 & 0.144288 & 0.000448 & -0.014548 & -0.008196 \\
18 & 0.059537 & -0.010645 & 0.162144 & 0.000514 & -0.016516 & -0.009316 \\
20 & 0.065878 & -0.011904 & 0.180001 & 0.000579 & -0.018483 & -0.010436 \\
\hline
\end{tabular}

(d) Impulse Response of Inflation

\begin{tabular}{cccccrr}
\hline Periods & \multicolumn{1}{c}{$\Delta \mathrm{FP}$} & $\Delta \mathrm{GR}$ & $\Delta(\log \mathrm{ED})$ & $\Delta(\log \mathrm{IF})$ & $\Delta(\log \mathrm{HE})$ & $\Delta(\operatorname{logNU})$ \\
\hline 1 & -0.030963 & -0.023768 & 0.055940 & 0.169484 & 0.000000 & 0.000000 \\
3 & -0.093189 & -0.086771 & 0.125662 & 0.408375 & -0.010124 & -0.011093 \\
5 & -0.182981 & -0.194271 & 0.184604 & 0.655992 & -0.026614 & -0.018671 \\
7 & -0.276682 & -0.311114 & 0.236035 & 0.905912 & -0.042424 & -0.026639 \\
9 & -0.370016 & -0.428124 & 0.286497 & 1.156210 & -0.057708 & -0.034374 \\
12 & -0.509738 & -0.603227 & 0.362290 & 1.531622 & -0.080524 & -0.045912 \\
14 & -0.602875 & -0.719928 & 0.412850 & 1.781885 & -0.095739 & -0.053605 \\
16 & -0.696013 & -0.836632 & 0.463409 & 2.032147 & -0.110956 & -0.061299 \\
18 & -0.789153 & -0.953337 & 0.513968 & 2.282410 & -0.126172 & -0.068993 \\
20 & -0.882292 & -1.070042 & 0.564527 & 2.532673 & -0.141389 & -0.076687 \\
\hline
\end{tabular}

(e) Impulse Response of Health Status

\begin{tabular}{ccccccc}
\hline Periods & \multicolumn{1}{c}{$\Delta \mathrm{FP}$} & $\Delta \mathrm{GR}$ & $\Delta(\log \mathrm{ED})$ & $\Delta(\log \mathrm{IF})$ & $\Delta(\log \mathrm{HE})$ & $\Delta(\operatorname{logN\mathrm {N}})$ \\
\hline 1 & 0.000791 & $-1.56 \mathrm{E}-05$ & 0.001688 & 0.000736 & 0.009122 & 0.000000 \\
3 & 0.000439 & -0.002774 & 0.003452 & 0.002072 & 0.022478 & 0.001406 \\
5 & -0.001426 & -0.008274 & 0.004274 & 0.003547 & 0.035893 & 0.002841 \\
7 & -0.003500 & -0.014319 & 0.004676 & 0.005229 & 0.049354 & 0.004333 \\
9 & -0.005548 & -0.020367 & 0.005024 & 0.006930 & 0.062848 & 0.005840 \\
12 & -0.008605 & -0.029415 & 0.005553 & 0.009479 & 0.083095 & 0.008103 \\
14 & -0.010643 & -0.035445 & 0.005908 & 0.011178 & 0.096592 & 0.009612 \\
16 & -0.012680 & -0.041475 & 0.006262 & 0.012877 & 0.110090 & 0.011120 \\
18 & -0.014718 & -0.047505 & 0.006617 & 0.014576 & 0.123587 & 0.012629 \\
20 & -0.016755 & -0.053535 & 0.006971 & 0.016275 & 0.137084 & 0.014137 \\
\hline
\end{tabular}


(f) Impulse Response of Nutrition Intake

\begin{tabular}{ccccccc}
\hline Periods & $\Delta \mathrm{FP}$ & \multicolumn{1}{c}{$\Delta \mathrm{GR}$} & $\Delta(\operatorname{logED})$ & $\Delta(\log \mathrm{IF})$ & $\Delta(\log \mathrm{HE})$ & $\Delta(\operatorname{logNU})$ \\
\hline 1 & 0.000251 & -0.000258 & 0.001454 & 0.000902 & -0.000460 & 0.003853 \\
3 & 0.000915 & -0.000156 & 0.003764 & 0.002032 & -0.000798 & 0.009364 \\
5 & 0.001946 & 0.000550 & 0.006334 & 0.003215 & -0.001100 & 0.015024 \\
7 & 0.003031 & 0.001390 & 0.009001 & 0.004342 & -0.001403 & 0.020667 \\
9 & 0.004110 & 0.002231 & 0.011681 & 0.005463 & -0.001714 & 0.026308 \\
12 & 0.005726 & 0.003487 & 0.015700 & 0.007147 & -0.002181 & 0.034768 \\
14 & 0.006802 & 0.004323 & 0.018379 & 0.008269 & -0.002492 & 0.040408 \\
16 & 0.007879 & 0.005160 & 0.021058 & 0.009391 & -0.002803 & 0.046048 \\
18 & 0.008956 & 0.005997 & 0.023737 & 0.010513 & -0.003115 & 0.051688 \\
20 & 0.010033 & 0.006834 & 0.026415 & 0.011636 & -0.003426 & 0.057328 \\
\hline
\end{tabular}

\subsection{Discussion of Findings}

The evidence presented in this article suggests that there exists a long-run relationship between the candidate variables of interest, such as economic growth, health status and nutrition intake, yet not education. Causality test indicated the causal relationship both in the short-and in the long run which conforms to what could have been expected based on the economic theory as well as some of the evidence from the existing literature. The findings show evidence of unidirectional causality in long run from education to economic growth. This suggests that, since education causes economic growth in the long run, improvements in the quality and quantity of manpower in schools might have positive effects on economic growth. Yet, this contradicts the findings of Omojimite (2010) about bidirectional causality between education and economic growth in Nigeria. What is more, contrary to Ogungbenle et al.'s (2014) evidence for the absence of causality between health (life expectancy) and economic growth in Nigeria, this study confirms the existence of twoway causal relationship between economic growth and health in the long run. In addition, there is also a causality test which indicates a unidirectional causality relationship that runs from the economic growth to health status in the short run. What follows is that a higher probability of reporting good health and lower prevalence for illness and diseases tends to encourage healthy workers to spend their income on good nutrition, dietary energy and protein supply which, in turn, can boost productivity and augment output growth of the economy. Likewise, empirical findings of this study provide evidence for a unidirectional causality that runs from nutrition intake to education in the short run. It means that nutrition intake has causal implications for education. It suggests that good nutrition and dietary energy supply tend to improve mental capacity, cognitive abilities and academic performance, which ultimately leads to boosting work productivity in the long run. The study also indicates a unidirectional causality relationship that runs from nutrition intake to health in the short run. There is also causality test which suggests a bidirectional causality relationship between the nutrition and the economic growth in the long run. The implication of this is that nutrition status of the workers has significant impact on the economic growth in the long run. The easier the workers' access 
to dietary energy and protein supply, the more productive and active they are, which consequently might increase output growth of the economy. This assumption is not in line with Dawson (2002) and Ogundari's (2011) findings, which suggested the existence of unidirectional causality from income to calorie intake for Pakistan and Nigeria. On the other hand, Tiffin and Dawson (2002) established bidirectional causality between calorie intake and income for Zimbabwe. Moreover, a one-way causal relationship has been found between education and health status in the short run, which supports the findings of Albert and Davia (2010) and Fonseca and Zheng (2011), which suggested unidirectional causality running from education to health in OECD countries and Saudi-Arabia. This may suggest that education does have significant influence on health both in the shortand in the long-run. It implies that healthy workers as well as the entire population of the given country gain more intellectual and educational power with the improvement of their health. Other results suggest unidirectional causality relationship running from fiscal policy to education in the short- as well as in the long-run. It means that effective fiscal policy might enhance quality of human capital in the economy. Access to quality education is a function of effective and efficient fiscal policy of the economy. Since monetary policy does not complement fiscal policy, it should be moderately designed in order to be an effective tool regulating and stabilizing the economy and protecting the economic welfare of its citizens.

\section{Concluding Remarks}

This paper investigates the causal relationship between health, education, nutrition and economic growth in Nigeria using quarterly time series data for the sample periods from 1990Q1 to 2013Q4 by means of VEC cointegration and Granger causality techniques. In addition, it also includes the forecast error variance decomposition and the impulse response function analyses in order to examine the dynamic interaction between economic growth, education, health status and nutrition intake, including fiscal policy and inflation rate as control variables. The findings suggest bidirectional causality relationship between the candidate variables of interest (health status, health nutrition and economic growth) in the long run. It implies that, by the adoption of Granger causality test it was possible to reveal inter-dependence and inter-connectivity of a long-run relationship between the variables of interest for the Nigerian economy,, demonstrating the existence of a long-run equilibrium relationship between all the variables selected in the study. In addition, it has been found that the short-run unidirectional causal relationship exists between the main variables.

There are also political implications of this study: a unidirectional causality relationship running from fiscal policy to education and health in the short run, which indicates that fiscal policy is imperative, therefore such policy needs to be treated as a fully controlled political variable. This study suggests that the government should be more aware 
of the importance of human development and welfare. This importance could be acknowledged by designing a sincere fiscal policy and complement with development policies. Effectiveness of these policies, together with the appropriate checks and balance strategies, would promote higher quality of life and social equality.

Finally, as government allocates resources to human development in the economy, they should be efficiently utilized in order to enhance productivity and boost economic growth. In order to achieve the desired objectives of human development, there is a need to design adequate mechanisms in order to ensure proper allocation of the limited resources and avoid their embezzlement by corrupt government officials.

The publication was co-financed by the "Excellent Science" program of the Minister of Science and Higher Education (currently Minister of Education and Science).

Dofinansowano z programu "Doskonała nauka" Ministra Nauki i Szkolnictwa Wyższego (obecnie Ministra Edukacji i Nauki).

\section{References}

Abdulai, A. and Aubert, D. (2004). Nonparametric and parametric analysis of calorie consumption in Tanzania. Food policy, 29(2):113-129.

Adeyemi, P. A. and Ogunsola, A. J. (2016). The Impact of Human Capital Development on Economic Growth in Nigeria: ARDL Approach. IOSR Journal of Humanities and Social Science (IOSR-JHSS), 21(3):1-7.

Afzal, M., Arshed, M. G., and Sarwar, K. (2013). Education, Health, Food Inflation and Economic Growth in Pakistan. Pakistan Economic and Social Review, 51(2):109-138.

Aka, B. F. and Dumont, J.-C. (2008). Health, Education and Economic Growth: Testing For Lon-grun Relationships and Causal Links. Applied Econometrics and International Development, 8(2).

Akinlo, A. E. and Egbetunde, T. (2010). Financial Development and Economic Growth: The Experience of 10 Sub-Saharan African Countries Revisited. The Review of Finance and Banking, 2(1).

Al-shihri, F. S. (2014). The Causal Relationship between Health and Education Expenditures in Saudi Arabia. International Journal of Scientific \& Engineering Research, $5(9): 672-675$. 
Albert, C. and Davia, M. A. (2010). Education is a key determinant of health in Europe: A Comparative Analysis of 11 Countries. Health Promotion International, 26(2):163-170.

Ämiri, $\ddot{A}$. and Linden, M. (2016). Income and total expenditure on health in OECD countries. Economics and Business Letters, 5(1):1-9.

Amiri, A. and Ventelou, B. (2012). Granger causality between total expenditure on health and GDP in OECD: Evidence from the Toda-Yamamoto approach. Economics Letters, 116(3):541-544.

Arcand, J.-L. et al. (2001). Undernourishment and Economic Growth: the Efficiency Cost of Hunger. FAO economic and social development paper. Food and Agriculture Organization of the United Nations.

Aslan, A., Menegaki, A. N., and Tugcu, C. T. (2015). Health and economic growth in high-income countries revisited: Evidence from an augmented production function for the period 1980-2009. Quality \& Quantity, 50(2):937-953.

Ayuba, A. J. (2014). The Relationship between Public Social Expenditure and Economic Growth in Nigeria: An empirical analysis. International Journal of Finance and Accounting, 3(3):185-191.

Cooray, A. (2013). Does Health Capital Have Differential Effects on Economic Growth? Applied Economics Letters, 20(3):244-249.

Dawson, P. J. (2002). Nutrition in Pakistan: Estimating the Economic Demand for Calories. Pakistan Journal of Nutrition, 1(1):64-66.

Fonseca, R. and Zheng, Y. (2011). The Effect of Education on Health: Cross-Country Evidence. RAND Working Paper No. WR-864 pg.25.

Hassan, M. S. and Kalim, R. (2012). The Triangular Causality Among Education, Health and Economic Growth: A Time Series Analysis of Pakistan. World Applied Sciences Journal, 18(2):196-207.

Johansen, S. (1988). Statistical Analysis of Cointegrating Vector. Journal of Economic Dynamics and Control, 12(2-3):231-254.

Johansen, S. and Juselius, K. (1990). Maximum Likelihood Estimation and Inference on Cointegration with Applications o the Demand for Money. Oxford Bulletin of Economics and statistics, 52(2):169-210.

Karlsen, J. and Rikardson, K. (2007). Nutrition Intake and Economic Growth: A causality study on five countries in Southern Africa. Unpublished master's thesis in economics, Stockholm School of Economics. 
Lucas, R. E. (1988). On The Mechanics of Economic Development. NBER Working Paper, 22(1).

Narayan, P. K. and Smyth, R. (2005). The Residential Demand for Electricity in Australia: An Application of the Bound Testing Approach to Cointegration. Energy Policy, 33(4):467-474.

Ogundari, K. (2011). Estimating Demand for Nutrients in Nigeria: A Vector ErrorCorrection Model. MPRA Papers No. 28930.

Ogundari, K. and Aromolaran, A. (2017). Nutrition and economic growth in sub-Saharan Africa: a causality test using panel data. International Journal of Development Issues, $16(2)$.

Ogungbenle, S., Olawumi, O., and Obasuyi, F. (2014). Life Expectancy, Public Health Spending and Economic Growth In Nigeria: A Vector Autoregressive (Var) Model. European Scientific Journal, 9(19).

Oh, W. and Lee, K. (2004). Energy Consumption and Economic Growth in Korea: Testing the Causality Relation. Journal of Policy Modeling, 26(8-9):973-981.

Omojimite, B. U. (2010). Education and economic growth in Nigeria: A Granger Causality Analysis. African Research Review, 4(3):90-108.

Rahman, M. M. (2011). Causal Relationship among Education Expenditure, Health Expenditure and GDP: A Case Study for Bangladesh. International Journal of Economics and Finance, 3(3):149-159.

Romer, P. M. (1990). Human Capital and Growth: Theory and Evidence. CarnegieRochester Conference Series on Public Policy, 32:251-285.

Şen, H., Kaya, A., and Alpaslan, B. (2018). Education, Health, and Economic Growth Nexus: A Bootstrap Panel Granger Causality Analysis for Developing Countries. Sosyoekonomi, 26(36):125-144.

Tang, C. F. (2011). Multivariate Granger Causality And The Dynamic Relationship Between Health Care Spending, Income And Relative Price Of Health Care In Malaysia. Hitotsubashi Journal of Economics, 52:199-214.

Tang, C. F. and Lai, Y. W. (2011). The Causal Relationship between Health and Education Expenditures in Malaysia. Theoretical \&s Applied Economics, 18(8):61-74.

Tiffin, R. and Dawson, P. (2002). The demand for calories: some further estimates from Zimbabwe. Journal of Agricultural Economics, 53(2):221-232. 
Ubi-Abai, I. P. and George-Anokwuru, C. C. (2018). Empirical Analysis of Determinants of Human Capital Formation: Evidence from the Nigerian Data. Journal of World Economic Research, 27(2):73-81.

Wang, K.-M. (2011). Health care expenditure and economic growth: Quantile panel-type analysis. Economic Modelling, 28(4):1536-1549.

Wang, X., Taniguchi, K., et al. (2003). Does Better Nutrition Enhance Economic Growth? Impact of Undernourishment. Nutrition Intake and Economic Growth, Food and Agriculture Organization: Rome.

Yun, W. S. and Yusoff, R. (2015). An Empirical Study of Education Expenditure, Health Care Expenditure and Economic Growth in Malaysia using Granger Causality Approach. Malaysian Journal of Business and Economics, 2(2):59-68. 